\title{
Electrohysterography for uterine monitoring during term labour compared to external tocodynamometry and intra-uterine pressure catheter
}

\author{
Citation for published version (APA): \\ Vlemminx, M. W. C., Thijssen, K. M. J., Bajlekov, G. I., Dieleman, J. P., van der Hout-van der Jagt, M. B., \& Oei, \\ S. G. (2017). Electrohysterography for uterine monitoring during term labour compared to external \\ tocodynamometry and intra-uterine pressure catheter. European Journal of Obstetrics \& Gynecology and \\ Reproductive Biology, 215, 197-205. https://doi.org/10.1016/j.ejogrb.2017.05.027
}

DOI:

10.1016/j.ejogrb.2017.05.027

Document status and date:

Published: 01/08/2017

\section{Document Version:}

Accepted manuscript including changes made at the peer-review stage

\section{Please check the document version of this publication:}

- A submitted manuscript is the version of the article upon submission and before peer-review. There can be important differences between the submitted version and the official published version of record. People interested in the research are advised to contact the author for the final version of the publication, or visit the DOI to the publisher's website.

- The final author version and the galley proof are versions of the publication after peer review.

- The final published version features the final layout of the paper including the volume, issue and page numbers.

Link to publication

\footnotetext{
General rights

- You may freely distribute the URL identifying the publication in the public portal. follow below link for the End User Agreement:

www.tue.nl/taverne

\section{Take down policy}

If you believe that this document breaches copyright please contact us at:

openaccess@tue.nl

providing details and we will investigate your claim.
}

Copyright and moral rights for the publications made accessible in the public portal are retained by the authors and/or other copyright owners and it is a condition of accessing publications that users recognise and abide by the legal requirements associated with these rights.

- Users may download and print one copy of any publication from the public portal for the purpose of private study or research.

- You may not further distribute the material or use it for any profit-making activity or commercial gain

If the publication is distributed under the terms of Article 25fa of the Dutch Copyright Act, indicated by the "Taverne" license above, please 


\section{TITLE PAGE}

2 Title: Electrohysterography for uterine monitoring during term labour compared to external

3 tocodynamometry and intra-uterine pressure catheter

4

5 Authors:

6 1. Marion W.C. VLEMMINX, MD ${ }^{1,2}$

7 2. Kirsten M.J. THIJSSEN, MD ${ }^{1,2}$

8

3. Galin I. BAJLEKOV, $\mathrm{MSc}^{2}$

9

4. Jeanne P. DIELEMAN, MSc, $\mathrm{PhD}^{3}$

5. M. Beatrijs VAN DER HOUT - VAN DER JAGT, MSc, PhD ${ }^{1,2}$

6. S. Guid OEI, MD, $\mathrm{PhD}^{1,2}$

${ }^{1}$ Department Obstetrics and Gynaecology, Máxima Medical Centre, Veldhoven, the

13 Netherlands. ${ }^{2}$ Department of Electrical Engineering, Eindhoven University of Technology, 14 Eindhoven, the Netherlands. ${ }^{3}$ MMC Academy, Máxima Medical Centre, Veldhoven, The 15 Netherlands.

16

17 Corresponding author: Marion W.C. Vlemminx, MD, Medical resident, Department of 18 Obstetrics and Gynaecology, Máxima Medical Centre, P.O. Box 7777, 5500MB, Veldhoven,

19 The Netherlands. Phone: +31 40888 8384. Fax: +31 408888387.

20 E-mail for communication: marionvlemminx@hotmail.com

21 E-mail for use in publication: marion.vlemminx@mumc.nl 
23 Condensation: Electrohysterography is an innovative technique for external uterine

24 monitoring that performs better than external tocodynamometry during first stage of labour, 25 and in obese women. 


\section{ABSTRACT}

Title: Electrohysterography for uterine monitoring during term labour compared to external tocodynamometry and intra-uterine pressure catheter

Authors: Vlemminx MWC, Thijssen KMJ, Bajlekov GI, Dieleman JP, van der Hout - van der Jagt MB, Oei SG.

Objective: Current uterine monitoring techniques have major drawbacks that could be avoided when using electrohysterography for uterine monitoring. Recently, a new electrohysterography method has been developed, providing a real-time tocogram on standard cardiotocography monitors. The diagnostic characteristics of this novel method need to be determined and compared to conventional methods. We hypothesised that electrohysterography can perform better than external tocodynamometry due to the adhesive properties of the contact electrodes (less motion sensitive), and the improved signal acquisition through subcutaneous tissue (less obesity sensitive).

Study design: In this prospective diagnostic accuracy study, uterine contractions of labouring women were simultaneously monitored by three different monitoring techniques: electrohysterography, external tocodynamometry, and intra-uterine pressure catheter as method of reference. We performed a two-hour measurement during first and/or second stage of term labour. The contractions of each method were automatically detected by a computerbased algorithm. As the applied method had not been described in literature before, an interim analysis was performed to minimise exposure to the invasive pressure catheter. The main outcome parameter was the sensitivity of electrohysterography in comparison to external tocodynamometry for uterine contraction detection, tested by the Wilcoxon signed rank test.

Results: Uterine contractions of 48 term labouring women were simultaneously monitored by electrohysterography, external tocodynamometry, and intra-uterine pressure catheter. The 
51 study was terminated after the interim analysis as the sensitivity of electrohysterography was

52 significantly higher compared to external tocodynamometry: median $89.5 \%$ (interquartile 53 range (IQR); 82-93) and 65.3\% (IQR; 53-81) respectively, $p<0.001$. In a subgroup analysis of 54 obese women $(n=15)$, the sensitivity of electrohysterography was significantly higher than 55 external tocodynamometry (median 88.4\% (IQR; 79-95) and 45.8\% (IQR; 38-61) 56 respectively, $p<0.001)$. Whereas in a subanalysis of second stage of labour $(n=8)$, 57 electrohysterography did not perform better than external tocodynamometry (median $72.8 \%$ 58 (IQR; 61-87) and 66.4\% (IQR; 46-75) respectively, $p=0.225$ ). Electrohysterography 59 registered 0.4 more contractions per 10 minutes than the intra-uterine pressure measurement $60 \quad(p<0.001)$ and 0.5 more contractions per 10 minutes than external tocodynamometry $61 \quad(p<0.001)$.

62 Conclusion: Electrohysterography has a higher sensitivity for uterine contraction detection 63 than external tocodynamometry during first stage of labour, in non-obese and obese women. 64 Electrohysterography identifies more contractions than conventional techniques.

66 Clinical trial registry: W3-study, Dutch Trial Registry, NTR5894

67 http://www.trialregister.nl/trialreg/admin/rctview.asp?TC=5894

68

69 Key words:

70 Cardiotocography (MeSH); Electrohysterography; External tocodynamometry; Intra-uterine 71 pressure catheter; Uterine monitoring (MeSH) 


\section{Introduction}

Uterine monitoring is one of the main intrapartum measurements. Recording of contractions is necessary to monitor labour progress, to evaluate the fetal heart rate pattern, and to detect excessive uterine activity (1-3). Unfortunately, current methods have major drawbacks.

External tocodynamometry (TOCO) is the present method of choice, being noninvasive and easy to apply. Although, its performance is hampered by obesity and maternal movements (4). Bakker et al. found good quality monitoring in only $2 \%$ of 41 external recordings during the last two hours of first stage, and in $34 \%$ of these recordings in the second stage (5). The current alternative to TOCO is an intra-uterine pressure catheter (IUPC), which provides quantitative information (6). However, this invasive method requires ruptured membranes and carries rare but serious risks such as placental and uterine perforation $(7,8)$. For these reasons, an accurate non-invasive alternative to enhance labour assessment is desired.

Electrohysterography (EHG) is a promising non-invasive technique which measures the uterine electrical currents through contact electrodes at the maternal abdomen (9). Several EHG studies have demonstrated a high correlation with the intra-uterine pressure (IUP) (10, 11). Mathematical models and technical improvements of the 21st century have enabled EHG to be applied as a real-time method for uterine monitoring during term labour $(12,13)$.

The aim of this study is to evaluate the performance of a novel EHG method not described in literature before. It entails an innovative EHG technology that provides a realtime tocogram on standard cardiotocography monitors and is therefore ready for daily use. Our hypothesis is that EHG can perform better than TOCO due to the adhesive properties of the contact electrodes (less motion sensitive), and the improved signal acquisition through subcutaneous tissue (less obesity sensitive) $(4,14,15)$. 


\section{Material and methods}

In this diagnostic accuracy study, uterine contractions of pregnant women were simultaneously monitored using three tocographic techniques: 1) EHG, 2) TOCO, and 3) IUPC as the method of reference. Term labouring women carrying a singleton foetus in cephalic presentation were eligible to participate. Labour was defined as $\geq 3 / 10$ min clinical contractions and $\geq 3 \mathrm{~cm}$ of dilation (2). Ruptured membranes and internal fetal monitoring were required to enable optimal placement of the external methods. Because of IUPC use, women at risk of infections were excluded: positive Group B streptococcus (urine or vagina), acute/chronic Hepatitis B or C, and HIV positive serology. Other exclusion criteria were: suspected placenta or vasa praevia, signs of intra-uterine infection or fetal distress, and abdominal dermatologic diseases.

Sensor-tipped IUPC’s were used (Koala, Clinical Innovations, Murray, Utah USA). Before insertion, an ultrasound was performed for placental localisation. Once placement in the amniotic cavity was established, both external methods were positioned.

EHG consisted of a single self-adhesive electrode patch connected to a translation module (Graphium and PUREtrace, Nemo Healthcare, Eindhoven, The Netherlands) (Figure 1). By manual palpation, we determined the optimal uterine interface (usually next to or above the umbilicus) and prepared the surface with abrasive sandpaper after which the patch was positioned. We measured the skin impedance (SIGGI II, MedCaT, Klazienaveen, Netherlands) and accepted values $<5.0 \mathrm{k} \Omega$. Next, data processing was performed by the translation module enclosing the following standard principles. Data from two independent electrodes were recorded at a $10 \mathrm{~Hz}$ sampling rate and combined into a single channel based on a physiological model of the myometrial conduction properties (12). The data were further processed by digital filtering techniques (which included a band pass filter between 0.3 and $0.8 \mathrm{~Hz}$ to suppress electrical activity from sources other than the uterus while preserving the 
121 main contraction power) and converted into a measure for uterine activity correlating with the

122 IUP based on a mathematical model described by Rabotti et al. (12). The module sent the 123 processed signal to a cardiotocography (CTG) monitor as a 'normal' tocogram.

124 Finally, the attending nurse placed TOCO after manual palpation, to determine the 125 optimal position of the transducer at uterine fundus. The nurse wrapped the transducer tightly 126 around the abdomen with an elastic belt.

127 To record three tocograms, we installed two additional CTG-monitors (Avalon FM30, 128 Philips Healthcare, Eindhoven, The Netherlands). All monitors were connected to the 129 electronic patient record system for data storage and time synchronisation (EZIS, Chipsoft, 130 Amsterdam, the Netherlands, sampling frequency: 4Hz). The IUPC output was combined 131 with the fetal heart rate pattern and displayed to the obstetric team, while TOCO and EHG 132 were displayed on an extra monitor. During the two-hour measurement, relevant incidents 133 such as maternal movements, vaginal examinations or oxytocin modifications were annotated. 134 To simulate standard care, nurses checked TOCO recordings every 30 minutes and 135 repositioned if necessary. A registration of at least 30 minutes was sufficient. When two hours 136 were completed, only IUPC was continued until the delivery.

\section{Contraction detection}

139 We used a computer-based algorithm for contraction detection developed by the Eindhoven 140 University of Technology (MatLab R2016B, MathWorks, Natick, Massachusetts, USA). The 141 algorithm (Figure 2), based on earlier literature (16-18), was tested before the beginning of 142 our study. In our original protocol we described a minimum contraction duration of $30 \mathrm{~s}$ (16). 143 While IUPC was our reference method, test measurements revealed non-detection of some 144 IUPC contractions. Therefore, the duration threshold in the protocol was adjusted to $25 \mathrm{~s}$ for 145 all three methods. Successive values of baseline tone were determined in a three-minute 
146

147

148

149

150

151

152

153

154

155

156

157

158

159

160

161

162

163

164

165

\section{Statistical analysis}

167 The performance characteristics of the tested EHG method have not been evaluated before.

168 The power analysis was therefore based on two prior studies that compared different EHG-

window and shifted with one-minute steps. Samples were recoded from the lowest to the highest value in each step. Hence, the threshold for contraction detection varied along with the amplitude of analysed signals. From the lowest $10 \%$ of samples, a mean value was calculated. We defined the threshold value by the baseline tone plus the value equal to $25 \%$ of signal range (i.e. difference between highest and lowest value) in the analysed window. The amplitude had to be $>2 x$ the threshold value (=50\%). Furthermore, a contraction was only recognised if enduring 25-180 s above the 25\% range. The output is available in Figure 2.

\section{Study outcomes}

The primary outcome was the sensitivity of EHG and TOCO for contraction detection defined as: true positive contractions in EHG or TOCO / contractions in IUPC * 100. We considered contractions as true positive when the contraction top was within $30 \mathrm{~s}$ from IUPC. Secondary study outcomes were: contraction frequency (per 10 minutes), positive predictive value, false positive/negative contraction ratio, and the contraction consistency index adopted from Jezewski et al. (17). A low consistency index means that the method over- or underestimates the frequency. Furthermore, we performed secondary group comparisons of non-obese to obese women and a comparison of the first and second stage of labour. Obesity was defined as a Body Mass Index (BMI) of $\geq 30 \mathrm{~kg} / \mathrm{m} 2$ before pregnancy and the second stage of labour as from full dilation. technologies with both IUPC and TOCO: Euliano 2013 and Hayes-Gill 2012 (14, 19). As the novel EHG method was expected to perform equally or better, we decided to perform an 
171 interim analysis to minimise the number of women being exposed to the invasive IUPC. The

172 sample size was calculated on a mean difference in sensitivity between EHG and TOCO of

$17319 \%$ (87\% and $68 \%$ respectively), with a standard deviation of $30 \%(14,19,20)$. To detect

174 this difference with a power of $80 \%$ and a type I error of $2.5 \%$ (for the interim analysis), a

175 sample size of 48 women was determined. An independent gynaecologist performed the

176 interim analysis.

177 Normality was tested using the Kolmogorov-Smirnov test. All paired parameters were 178 analysed using a paired two-sided t-test for normally distributed data or the Wilcoxon signed 179 rank test for not-normally distributed data. Differences between unpaired groups have been 180 examined using an unpaired two-sided t-test for normally distributed data and the Mann181 Whitney U-test for not-normally distributed data. The contraction frequency difference 182 between EHG/IUPC and TOCO/IUPC were visualised in histograms. Two-sided p-values $183<0.05$ were considered statistically significant. Statistical evaluations were conducted in SPSS 18420 statistics for Windows (IBM, New York, USA). Obstetric parameters have been extracted 185 from the patient record. In case of missing data, we only analysed the available data.

\section{Ethical considerations}

188 The Institutional Review Board of Máxima Medical Centre approved the protocol on the $15^{\text {th }}$ 189 of July 2014 (NL48951.015.14) and the study was registered in the Dutch trial register 190 (NTR5894). All women signed informed consent. Researchers MV and KT recruited women 191 exclusively in our hospital and carried out all measurements. 
193

194

195

196 197 study.

\section{Results}

A total of 48 term pregnant women were enrolled between July 2014 and September 2015. The interim analysis was performed in January 2016 and resulted in a $p$-value of $<0.001$ regarding the difference in sensitivity between EHG and TOCO, allowing us to terminate the

About 400 women were eligible for inclusion. Common reasons for non-participation were: not willing to be confined to bed, anxiety for their first delivery, and the IUPC risks. Twelve women signed informed consent, but were not measured because: labour went too quick (5/12), women were only willing to participate after epidural (3/12), no researcher was available (1/12), a woman was in too much pain (1/12) and in two cases the reasons were unknown. Of the 49 started measurements, one participant was excluded because she gave birth within the first 30 minutes of recording. There were no dropouts due to technical problems, no women lost during follow-up, no adverse events and no skin reactions. Of three women, the body weight during labour was unknown. There were no other missing data. The baseline characteristics are available in Table 1 . Of the 48 included women, 58.5\% were nulliparous, $70.8 \%$ had induction of labour, and 75.0\% had labour analgesia. Figure 3 shows the results of three tocograms in one participant.

The median sensitivity of EHG was 89.5\% (interquartile range (IQR); 82-93), which was higher than the median sensitivity of TOCO, 65.3\% (IQR; 53-81), $p<0.001$ (Table 2). The contraction consistency index, even as the false positive and false negative contraction ratio were significantly better in EHG (Table 2). The EHG peak was $2.0 \mathrm{~s}$ later than IUPC, while the TOCO peak was 0.6 s before IUPC (Table 2).

On average, IUPC registered 3.8 contractions per 10 minutes. The EHG method registered $0.4 / 10 \mathrm{~min}$ more compared to IUPC $(p<0.001)$ and $0.5 / 10 \mathrm{~min}$ more than TOCO $(p<0.001)$ (Table 1). These 'additional' contractions in EHG are considered false positive in 
218 further analyses. In the histograms presenting the difference in contraction frequency of the

219 external methods per women, EHG revealed an overall overestimation whereas TOCO

220 showed both an over- and underestimation varying per measurement (Figure 4).

221 Moreover, the sensitivity differences were consistent in the obesity analyses. EHG 222 performed significantly better than TOCO in both non-obese ( $n=33)$ and obese women $(n=15)$

223 (Table 2). Additionally, both techniques showed a decrease of sensitivity in case of maternal 224 obesity, whereas only TOCO was significantly affected: EHG median $-1.6 \%, p=0.374$ and 225 TOCO median $-27.2 \%, p=0.001$ (Table 2 and Figure 5).

226 Finally, we compared EHG and TOCO measurements in the first and second stage 227 (n=8). The median sensitivity of EHG was significantly lower during the second stage ($22818.5 \%, p=0.025)$, while TOCO was not significantly affected $(-3.0 \%, p=0.123)$. 


\section{Comment}

EHG demonstrated a high sensitivity for contraction detection and performed better than TOCO during the first stage, in non-obese and obese women. Additionally, the contraction frequency was higher in EHG compared to both conventional techniques.

The main strength is the study design. We applied three techniques simultaneously, used a computerised analysis for contraction detection, and the women were continuously observed. Moreover, unlike earlier studies, our participants were included irrespective of the available monitoring technique, such as indication for IUPC use or whether TOCO was working properly $(14,19,20)$. Additionally, we are the first to evaluate the performance of this real-time EHG method, that can be used on standard monitoring systems.

We are aware of some limitations. We included more women with induction of labour and epidural analgesia which could have increased the sensitivity results. Furthermore, the subanalyses were performed in small groups which could compromise the statistical power. Yet, post-hoc calculation of the obesity analysis revealed a power of $100 \%$ for detecting the difference in sensitivity between EHG and TOCO.

Our study results agree with previous EHG studies showing that EHG can improve external uterine monitoring compared to TOCO (sensitivity between $86.0 \%$ and $94.2 \%$ for EHG and between $46.0 \%$ and $73.6 \%$ for TOCO) $(14,19,21,22)$. However, each EHG technology entails numerous technical aspects such as the electrode configuration, the applied filtering technique, and the type of skin preparation. Therefore, previous studies are not directly applicable to this EHG method.

IUPC is currently being considered as the gold standard. However, IUPC is not $100 \%$ reliable due to inadequate positioning in the amniotic cavity or due to relocation (especially in the second stage) $(23,24)$. Furthermore, a randomised controlled trial comparing IUPC with TOCO revealed no difference in the operative delivery rate (28). Yet, there was a high 
254 crossover from TOCO to IUPC, especially in obese women, and women with a previous 255 uterine scar were excluded.

Our study reveals that EHG detects more contractions than IUPC. The first explanation regards electrical artefacts, due to maternal movements, electrode detachment, and pressure on the patch. The investigated method configures these 'artefact-based 259 contractions' in a specific waveform, which can be recognised by experienced users (Figure 260 6). In our EHG monitoring strips, we identified 50 artefacts of which $68 \%$ could be explained 261 by mechanical causes. Yet, these artefacts covered only $11 \%$ of all the additional EHG 262 contractions. Additionally, this first hypothesis is supported by a decreasing EHG sensitivity 263 during the second stage. However, with exception of the amplitude in some cases, the EHG 264 contraction waveforms did not significantly change during maternal pushing (see Figure 7).

265 The second explanation is that EHG reports the origin of contractions (electrical 266 activity) instead of the global effect (IUP). These 'extra' contractions might represent local 267 electrical activity, which is not conducted throughout the whole myometrium and therefore 268 does not change the IUP. During our observations, some women reported pain which was 269 accompanied by EHG activity while the IUP did not change. If this theory is correct, then 270 EHG could provide extra information which should be considered when interpreting EHG271 tocograms.

272 The described EHG method can be easily connected to standard CTG-monitors and 273 provides a real-time tocogram. The average peak delay is two seconds compared to IUPC and 274 is potentially due to data calculation. We consider this delay clinically irrelevant as the 275 average contraction duration is one minute and late decelerations start more than twenty 276 seconds after the contraction onset $(3,25)$.

277 Our main concern is that the uterine activity awareness might have decreased over 278 years by a habituation to inadequate tocograms. Until there is sufficient cervical dilation and 
279 ruptured membranes for IUPC, TOCO is currently the only available modality. Nonetheless, 280 uterine monitoring is a key measure for labour progress and interpretation of the fetal 281 condition $(1,6)$. Improvement of uterine monitoring could be of clinical benefit $(26,27)$, yet 282 the fetal heart rate patterns in regard to the EHG tocogram have not been assessed. Therefore, 283 the effect on perinatal outcome needs to be further investigated $(27,28)$.

284 In conclusion, EHG is a promising non-invasive alternative for uterine monitoring 285 during term labour. 
286 Conflicts of interest notification: Máxima Medical Centre is a research partner of Nemo

287 Healthcare. Author professor Oei is gynaecologist and head of the obstetric department of

288 Máxima Medical Centre and leader of the fundamental perinatology research group from

289 Eindhoven University of Technology, the scientific research from which the described EHG 290 method and the company Nemo Healthcare has originated. Professor Oei has no affiliations 291 with or involvement in Nemo Healthcare with any financial interest. During the study, authors 292 M.V., K.T., and B.vd.H. were paid by a grant of the independent Dutch Foundation 'De 293 Weijerhorst'. From 2016, author K.T. is being paid by a grant from the European Framework 294 Research and Innovation Program ‘Horizon 2020’ (Grant number 719500). Authors G.B. and 295 J.D. have no conflicts of interest.

\section{Acknowledgement:}

298 The study has been financially supported by the Dutch Foundation 'Stichting De 299 Weijerhorst'. The sponsor was not involved in the study set-up, collection, analysis or 300 interpretation of the data.

302 Abbreviations:

$303-$ BMI = body mass index

$304-$ CTG = cardiotocography

$305-$ EHG = electrohysterography

306 - IUP = intra-uterine pressure

307 - IUPC = intra-uterine pressure catheter

$308-$ IQR = interquartile range

$309-$ TOCO = external tocodynamometry 


\section{References:}

312 1. Bakker PC, van Geijn HP. Uterine activity: implications for the condition of the 313 fetus. J Perinat Med. 2008;36:30-7.

314 2. Reuwer P, Bruinse H, Franx A, editors. Proactive support of labor: Cambridge 315 University Press; 2009.

316 3. Ayres-de-Campos D, Spong CY, Chandraharan E. FIGO consensus guidelines on 317 intrapartum fetal monitoring: Cardiotocography. Int J Gynaecol Obstet. 2015;131:13-24.

318 4. Euliano TY, Nguyen MT, Marossero D, et al. Monitoring contractions in obese 319 parturients: electrohysterography compared with traditional monitoring. Obstet 320 Gynecol. 2007;109:1136-40.

321 5. Bakker PC, Zikkenheimer M, van Geijn HP. The quality of intrapartum uterine 322 activity monitoring. J Perinat Med. 2008;36:197-201.

323 6. Bakker PC, Van Rijswijk S, van Geijn HP. Uterine activity monitoring during labor. 324 J Perinat Med. 2007;35:468-77.

325 7. Wilmink FA, Wilms FF, Heydanus R, et al. Fetal complications after placement of 326 an intrauterine pressure catheter: a report of two cases and review of the literature. J 327 Matern Fetal Neonatal Med. 2008;21:880-3.

328 8. Rood KM. Complications associated with insertion of intrauterine pressure 329 catheters: an unusual case of uterine hypertonicity and uterine perforation resulting in 330 fetal distress after insertion of an intrauterine pressure catheter. Case Rep Obstet 331 Gynecol. 2012;2012:517461.

332 9. Ye-Lin Y, Garcia-Casado J, Prats-Boluda G, et al. Automatic identification of motion 333 artifacts in EHG recording for robust analysis of uterine contractions. Comput Math 334 Methods Med. 2014;2014:470786.

335 10. Euliano T, Skowronski M, Marossero D, et al. Prediction of intrauterine pressure 336 waveform from transabdominal electrohysterography. J Matern Fetal Neonatal Med. 337 2006;19:811-6.

338 11. Nixon WC, Smyth CN, Myerscough PR, et al. Discussion: dynamics of the uterus 339 and their clinical applications. Proc R Soc Med. 1955;48:675-81.

340 12. Rabotti C, Mischi M, van Laar JO, et al. Estimation of internal uterine pressure by 341 joint amplitude and frequency analysis of electrohysterographic signals. Physiol Meas. 2008;29:829-41. 
343 13. Rooijakkers MJ, Rabotti C, Oei SG, et al. Low-complexity intrauterine pressure 344 estimation using the Teager energy operator on electrohysterographic recordings. 345 Physiol Meas. 2014;35:1215-28.

346 14. Euliano TY, Nguyen MT, Darmanjian S, et al. Monitoring uterine activity during 347 labor: a comparison of 3 methods. Am J Obstet Gynecol. 2013;208:66 e1-6.

348 15. De Luca CJ. The Use of Surface Electromyography in Biomechanics. J Appl 349 Biomech. 1997;13:135-63.

350 16. Horoba K, Jezewski J, Wrobell J, et al. Algorithm for detection of uterine 351 contractions form electrohysterogram. Proceedings of the 23rd Annual EMBS 352 International Conference; October 25-28; Istanbul, Turkey.2001.

353 17. Jezewski J, Horoba K, Matonia A, et al. Quantitative analysis of contraction 354 patterns in electrical activity signal of pregnant uterus as an alternative to mechanical 355 approach. Physiol Meas. 2005;26:753-67.

356 18. Bajlekov GI, Rabotti C, Oei SG, et al. Electrohysterographic detection of uterine 357 contractions in term pregnancy. Conf Proc IEEE Eng Med Biol Soc. 2015;2015:5851-4.

358 19. Hayes-Gill BR, Hassan M, Mirza FG, et al. Accuracy and reliability of uterine 359 contraction identification using abdominal suface electrodes. Clin Med Insights Womens 360 Health. 2012;5:65-75.

361 20. Cohen WR, Hayes-Gill B. Influence of maternal body mass index on accuracy and 362 reliability of external fetal monitoring techniques. Acta Obstet Gynecol Scand. $3632014 ; 93: 590-5$.

364 21. Hadar E, Biron-Shental T, Gavish O, et al. A comparison between electrical uterine 365 monitor, tocodynamometer and intra uterine pressure catheter for uterine activity in 366 labor. J Matern Fetal Neonatal Med. 2015;28:1367-74.

367 22. Euliano TY, Nguyen MT, Darmanjian S, et al. Monitoring Uterine Activity during 368 Labor: Clinician Interpretation of Electrohysterography versus Intrauterine Pressure 369 Catheter and Tocodynamometry. Am J Perinatol. 2016;33:831-8.

370 23. Lind BK. Complications caused by extramembranous placement of intrauterine 371 pressure catheters. Am J Obstet Gynecol. 1999;180:1034-5.

372 24. Dowdle MA. Comparison of two intrauterine pressure catheters during labor. J 373 Reprod Med. 2003;48:501-5.

374 25. Nijhuis JG, Essed GGM, Geijn HPvd, et al., editors. Foetale bewaking. Amsterdam: 375 Reed Business; 2013. 
376 26. Lucovnik M, Kuon RJ, Garfield RE. Assessment of parturition with cervical light377 induced fluorescence and uterine electromyography. Comput Math Methods Med. $378 \quad 2013 ; 2013: 165913$.

379 27. Maul H, Maner WL, Saade GR, et al. The physiology of uterine contractions. Clin 380 Perinatol. 2003;30:665-76, v.

381 28. Vlemminx MW, de Lau H, Vullings R, et al. [Electrohysterography. A promising 382 alternative for monitoring contractions]. Ned Tijdschr Geneeskd. 2015;159:A8535.

383

384 


\section{Supporting information figures}

Figure 1: The applied electrohysterography method.

1A: Abdominal electrode patch and EHG translation module.

1B: Positioning of the patch at the maternal abdomen, which can be below, next to, or above the umbilicus for proper interface with the uterine muscle.

391 Reprinted with permission from Nemo Healthcare, Eindhoven, The Netherlands.

Figure 2: The algorithm and output of the computer-based contraction detection.

394 The left figure shows the applied algorithm for contraction detection. From the lowest $10 \%$ of 395 samples, a mean value was calculated. The threshold value was defined by the baseline tone 396 plus the value equal to $25 \%$ of signal range (i.e. difference between highest and lowest value) 397 in the analysed window. The amplitude had to be $>2 x$ the threshold value $(=50 \%)$. 398 Furthermore, a contraction was only recognised if enduring 25-180 s above the 25\% range. 399 The output (right) represents 30 minutes of registration with intra-uterine pressure catheter (y400 axis in millimetre of Mercury). The peaks are marked in seconds from the beginning of the 401 measurement. Underneath the contractions are three rows of blocks. From top to bottom, these blocks represent: 1) actual contraction detection, 2) value equal to or more than $50 \%$ of signal range, and 3) value equal to or more than $25 \%$ of the signal range.

405 Figure 3: The result of real-time uterine monitoring with three different tocographic 406 techniques in one pregnant woman.

407 The figure represents a measurement of 15 minutes. From top to bottom, the lines represent:

408 fetal heart rate, intra-uterine pressure catheter, electrohysterography and external 409 tocodynamometry. 
410 Figure 4: Histograms showing the average differences in contraction frequency of 411 electrohysterography and external tocodynamometry by comparison to the intra-uterine 412 pressure catheter.

413 The vertical line (zero) represents a perfect correlation in number of contractions/10 minutes 414 between the external methods and IUPC. On average, IUPC registered 3.8 contractions per 10 415 minutes. The EHG method registered 0.4 contractions per 10 minutes more compared to 416 IUPC $(\mathrm{p}<0.001)$ and 0.5 per 10 minutes more than TOCO $(\mathrm{p}<0.001)$.

417 (EHG, electrohysterography; TOCO, external tocodynamometry; IUPC, intra-uterine pressure 418 catheter)

Figure 5: Sensitivity of electrohysterography and external tocodynamometry in pregnant women with and without maternal obesity.

422 The box plots represent the interquartile range from the $25^{\text {th }}$ till the $75^{\text {th }}$ quartile and the 423 horizontal line in the box shows the median. Each box is lined by the minimum and 424 maximum. The circles are cases with outlying values, whereas the asterisk is a case with an 425 extreme outlying value. In case of maternal obesity, both techniques showed a decrease in 426 median sensitivity, EHG $-1.6 \%$, $\mathrm{p}=0.374$ and TOCO $-27.2 \%, \mathrm{p}=0.001$.

427 (EHG, electrohysterography; TOCO, external tocodynamometry)

429 Figure 6: Artefact in an electrohysterography tocogram.

430 An artefact can be recognised by a small and steep contraction with a horizontal flat top. In 431 this electrohysterography tocogram, the middle contraction represents an artefact.

433 Figure 7: Electrohysterography during the second stage of labour. 
434 The figure represents a study measurement of 30 minutes. The labouring woman started 435 pushing in the middle of this cardiotocogram, after which no significant change of the 436 tocogram was observed. The lines from top to bottom represent: fetal heart rate, intra-uterine 437 pressure catheter, electrohysterography, and external tocodynamometry. 


\begin{tabular}{|c|c|}
\hline Patient characteristic & Pregnant women $n=48$ \\
\hline Maternal age (y) & $31.9+4.1$ \\
\hline Race & \\
\hline White & $45(93.8)$ \\
\hline Other & $3(6.3)$ \\
\hline Body mass index $(\mathrm{kg} / \mathrm{m} 2)$ & \\
\hline Before pregnancy & $28.5+8.0$ \\
\hline During measurement & $32.8 \pm 6.8$ \\
\hline Parity & \\
\hline Nulliparous & $28(58.3)$ \\
\hline Multiparous & $20(41.7)$ \\
\hline Gestational age (weeks+days) & $39+3(37+1-41+6)$ \\
\hline Start of labour & \\
\hline Spontaneous onset & $14(29.2)$ \\
\hline Induction of labour & $34(70.8)$ \\
\hline Oxytocin usage & \\
\hline No & $12(25.0)$ \\
\hline Yes & $36(75.0)$ \\
\hline Labour analgesia & \\
\hline No analgesia & $12(25.0)$ \\
\hline Epidural analgesia & $33(68.8)$ \\
\hline Remifentanil & $3(6.3)$ \\
\hline Duration measurement (min) & $105.1(30-150)$ \\
\hline Cervical dilatation $(\mathrm{cm})$ & \\
\hline Start measurement & $4.9(3-10)$ \\
\hline Stop measurement & $7.6(3-10)$ \\
\hline Mode of delivery & \\
\hline Spontaneous vaginal delivery & $32(66.7)$ \\
\hline Vacuum delivery & $7(14.6)$ \\
\hline Caesarean delivery & 9 (18.8) \\
\hline Neonatal birthweight (g) & $3550.2+503.5$ \\
\hline Detected contractions (number total) & \\
\hline Intra-uterine pressure catheter & 1902 \\
\hline
\end{tabular}




\begin{tabular}{|c|c|c|c|c|}
\hline Diagnostic characteristic & EHG & TOCO & Difference & $p$-Value \\
\hline Sensitivity overall $(n=48)(\%)$ & $89.5(82-93)$ & $65.3(53-81)$ & 24.2 & $p<0.001^{a}$ \\
\hline -- Sensitivity non-obese women $(n=33)(\%)$ & 90.0 (86-93) & $73.0(59-87)$ & 17.0 & $p<0.001^{a}$ \\
\hline -- Sensitivity obese women* $(n=15)(\%)$ & $88.4(79-95)$ & $45.8(38-61)$ & 42.6 & $p=0.001^{a}$ \\
\hline$\sim$ Sensitivity first stage $(n=8)(\%)$ & $91.3(88-98)$ & $69.4(63-89)$ & 21.9 & $p=0.018^{a}$ \\
\hline$\sim$ Sensitivity second stage se $^{* *}(n=8)(\%)$ & $72.8(61-87)$ & $66.4(46-75)$ & 6.4 & $p=0.225^{a}$ \\
\hline Contraction consistency index $\dagger(n=48)(\%)$ & $85.9(73-90)$ & $65.1(52-84)$ & 20.8 & $p<0.001^{a}$ \\
\hline Positive predictive value $(n=48)(\%)$ & $80.8(64-90)$ & $67.2(52-86)$ & 13.6 & $p<0.001^{a}$ \\
\hline False positive contraction ratio $\neq(n=48)(\%)$ & $19.2(10-36)$ & $32.8(14-48)$ & 13.6 & $p<0.001^{a}$ \\
\hline False negative contraction ratio $\ddagger(n=48)(\%)$ & $9.8(6-15)$ & $33.6(18-52)$ & 23.8 & $p<0.001^{a}$ \\
\hline Top of contraction $(n=48)(\mathrm{sec})$ & $2.0 \pm 4.0$ & $-0.6 \pm 4.7$ & 2.6 & $p=0.002^{b}$ \\
\hline $\begin{array}{l}\text { EHG, electrohysterography; TOCO, external t } \\
\text { Data are median with (interquartile range) or } \mathrm{n} \\
* \text { Maternal obesity was defined as BMI } \geq 30 \mathrm{k} \\
* * \text { Second stage was defined as from full dilat } \\
\dagger \text { Contraction consistency index = true positiv } \\
+ \text { contractions EHG or TOCO). } \\
\ddagger \text { False positive and false negative contrac } \\
\text { respectively / total contractions in EHG or TO } \\
{ }^{a} \text { Wilcoxon Signed rank test. }{ }^{b} \text { Two-sided paire }\end{array}$ & $\begin{array}{l}\text { odynamometry } \\
\text { an with } \pm \text { stanc } \\
\mathrm{m} 2 \text { before preg } \\
\text { ontractions in } \\
* 100 \text {. } \\
\text { student t-test. }\end{array}$ & $\begin{array}{l}\text { Ird deviation (o } \\
\text { lancy. } \\
\text { HG or TOCO positive or }\end{array}$ & alse negativ & $\begin{array}{l}\text { ions in IUPC } \\
\text { contractions }\end{array}$ \\
\hline
\end{tabular}



<smiles>CCc1ccccc1CC(C)Cc1ccccc1</smiles> 


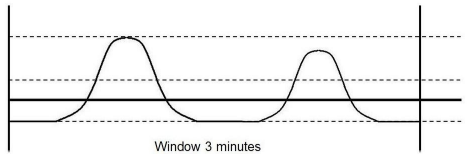

Highest value

$50 \%$ Threshold 25\% Threshold Baseline

Window 3 minutes 


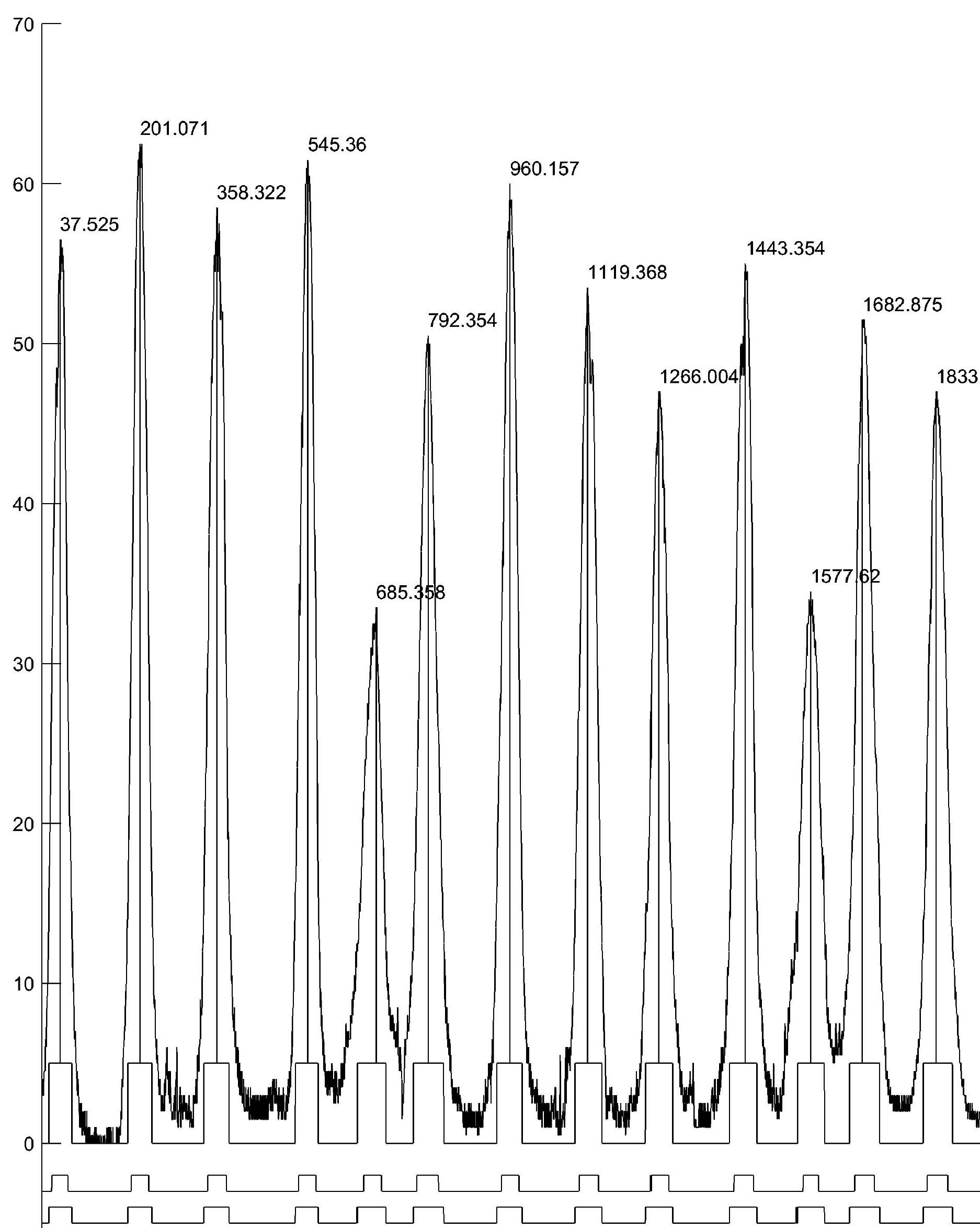



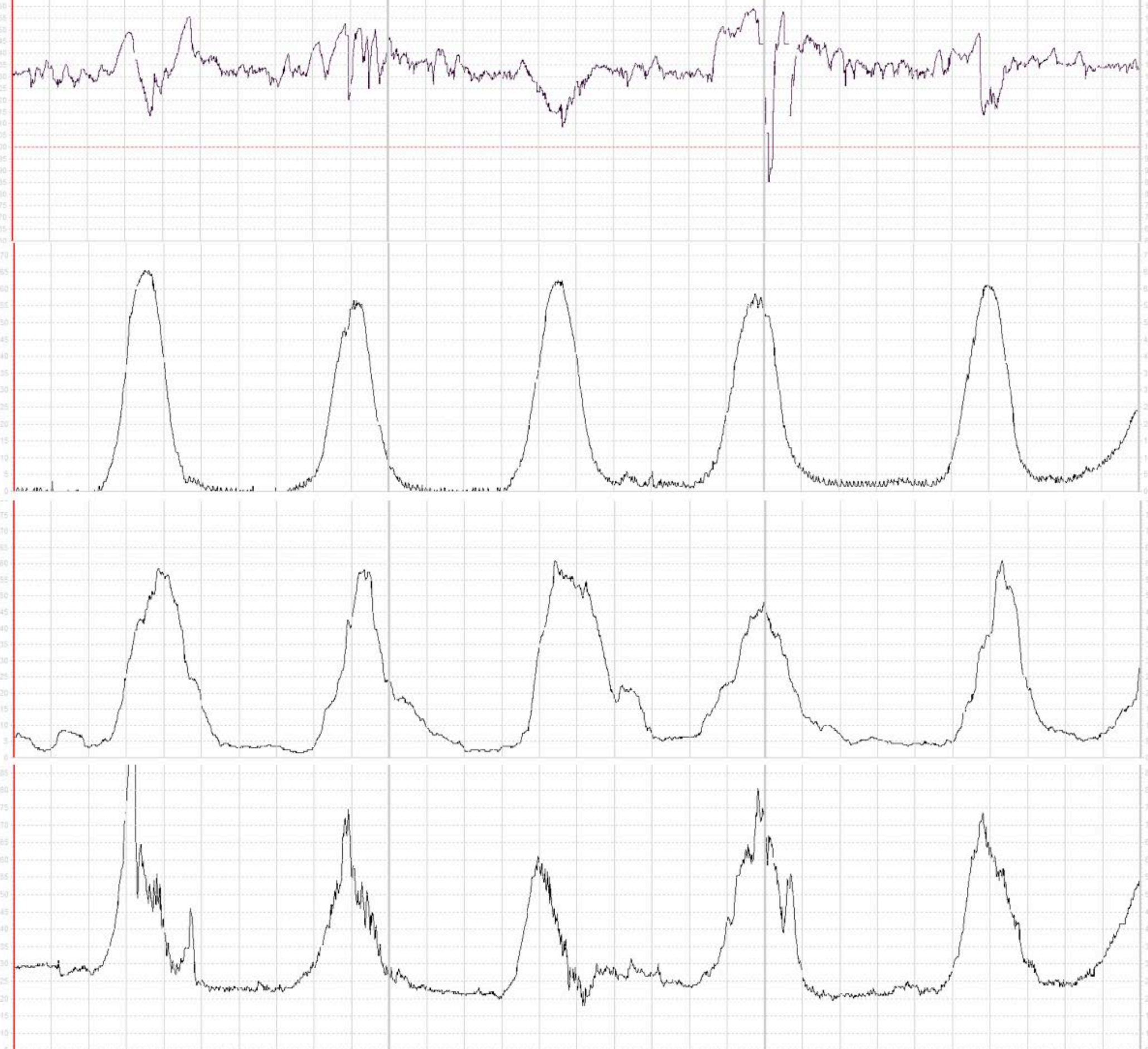


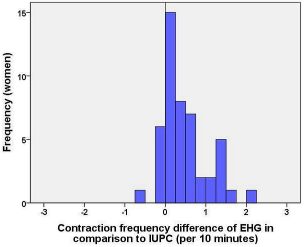




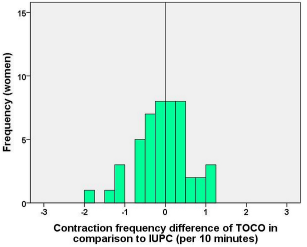




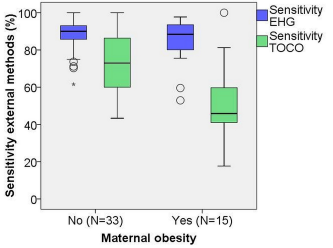




\section{CTG TOCO (2 cm - $1 \mathrm{~min})$}

TOCO
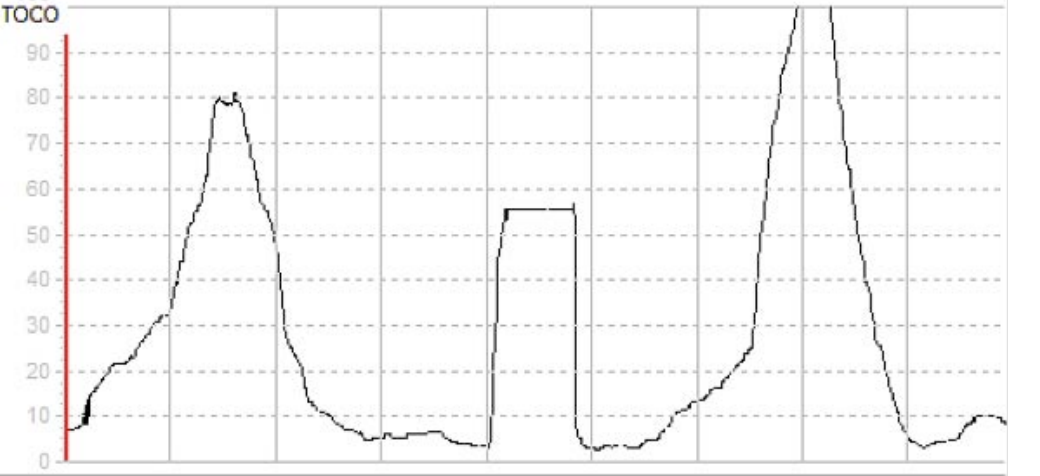


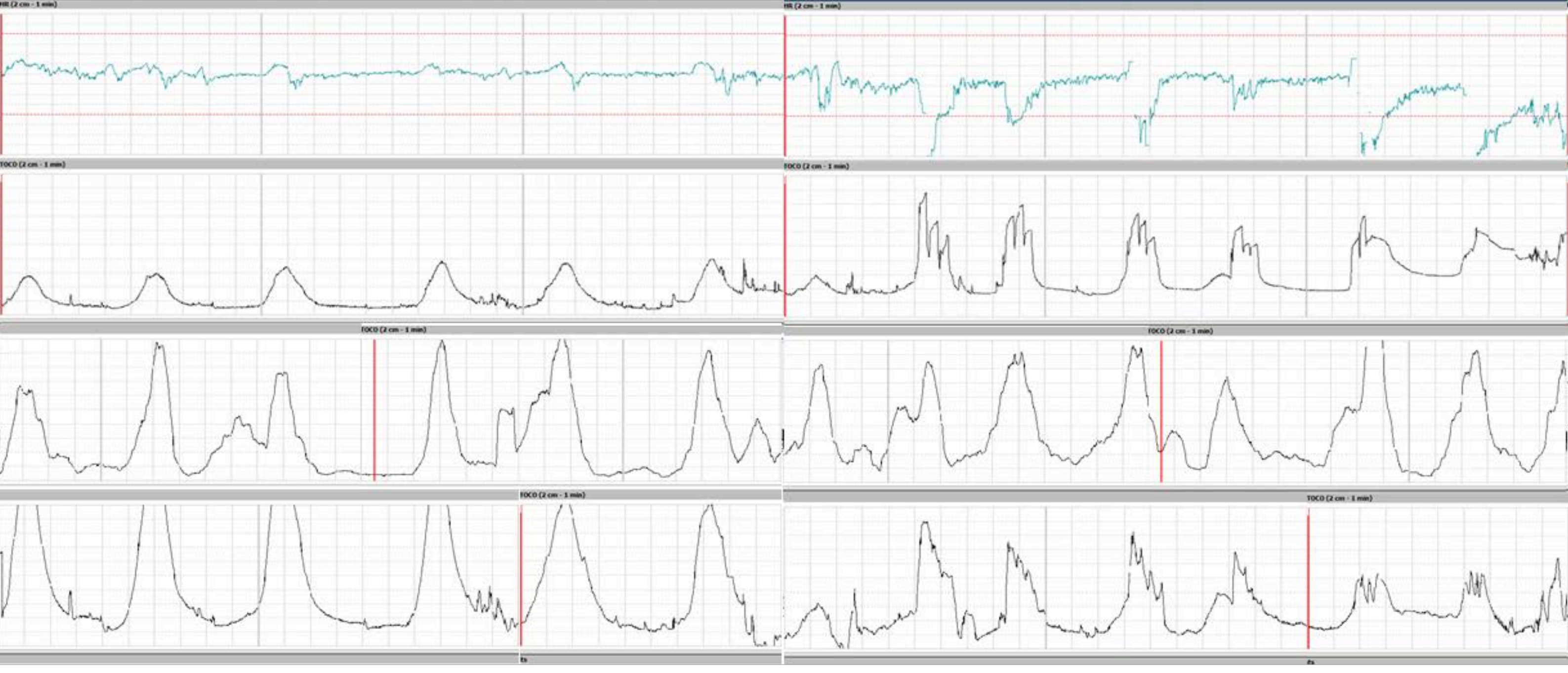

